\title{
Rawls on Liberty and Its Priority
}

\author{
H.L.A. Hart $\dagger$
}

\section{INTRODUGTORY}

No book of political philosophy since I read the great classics of the subject has stirred my thoughts as deeply as John Rawls's $A$ Theory of Justice. But I shall not in this article offer a general assessment of this important and most interesting work. I shall be concerned with only one of its themes, namely, Rawls's account of the relationship between justice and liberty, and in particular with his conception that justice requires that liberty may only be limited for the sake of liberty and not for the sake of other social and economic advantages. I have chosen this theme partly because of its obvious importance to lawyers who are, as it were, professionally concerned with limitations of liberty and with the justice or injustice of such limitations. I choose this theme also because this part of Rawls's book has not, I think, so far received, in any of the vast number of articles on and reviews of the book which have been published, the detailed attention which it deserves. Yet, as Sidgwick found when he considered a somewhat similar doctrine ascribing priority to liberty over other values, such a conception of liberty, though un: doubtedly striking a responsive chord in the heart of any liberal, has its baffling as well as its attractive aspect, ${ }^{1}$ which becomes apparent when we consider, as Rawls intends that we should, what the application of this doctrine would require in practice.

Part of what follows is concerned with a major question of interpretation of Rawls's doctrine and the rest is critical. But I am very conscious that I may have failed to keep constantly in view or in proper perspective all the arguments which Rawls, at different places in this long and complex work, concentrates on the points which I find unconvincing. I would not therefore be surprised if my interpretation could be corrected and my criticisms answered by some further explanation which the author could supply. Indeed I do not write to confute, but mainly in the hope that in some of the innumerable future

$\uparrow$ Research Fellow of University College, Oxford.

1 H. SIDGwick, THE METHods of ETHICs (7th ed. 1907) Book III, Ch. V, § 4. "I admit that it commends itself much to my mind. . . But when I endeavour to bring it into closer relation to the actual circumstances of human society it soon comes to wear a different aspect." 
editions of this book Rawls may be induced to add some explanation of these points.

I hope that I can assume that by now the main features of Rawls's $A$ Theory of Justice are familiar to most readers, but for those to whom it is not, the following is a minimum account required to make this article intelligible.

First, there is what Rawls terms the "Main Idea." This is the striking claim that principles of justice do not rest on mere intuition yet are not to be derived from utilitarian principles or any other teleological theory holding that there is some form of good to be sought and maximised. Instead, the principles of justice are to be conceived as those that free and rational persons concerned to further their own interests would agree should govern their forms of social life and institutions if they had to choose such principles from behind "a veil of ignorance" -that is, in ignorance of their own abilities, of their psychological propensities and conception of the good, and of their status and position in society and the level of development of the society of which they are to be members. The position of these choosing parties is called "the original position." Many discussions of the validity of this Main Idea have already appeared and it will continue to be much debated by philosophers, but for the purposes of this article I shall assume that if it could be shown that the parties in the original position would choose the principles which Rawls identifies as principles of justice, that would be a strong argument in their favour. From the Main Idea Rawls makes a transition to a general form or "general conception" of the principles that the parties in the original position would choose. This general conception of justice is as follows:

All social values-liberty and opportunity, income and wealth, and the bases of self-respect-are to be distributed equally unless an unequal distribution of any, or all, of these values is to everyone's advantage. ${ }^{2}$

This general conception of justice, it should be observed, refers to the equal distribution of liberty but not to its maximisation or extent. However, most of the book is concerned with a special interpretation of this general conception which refers both to the maximisation and the equality of liberty. The principal features of this special conception of justice are as follows:

First Principle ["the principle of greatest equal liberty"] ${ }^{3}$

Each person is to have an equal right to the most extensive total

2 P. 62.

3 P. 124. 
system of equal basic liberties compatible with a similar system of liberty for all.

Second Principle

Social and economic inequalities are to be arranged so that they are ... to the greatest benefit of the least advantaged .... .4

To these two principles there are attached certain priority rules of which the most important is that liberty is given a priority over all other advantages, so that it may be restricted or unequally distributed only for the sake of liberty and not for any other form of social or economic advantage.

To this account there must be added two points specially relevant to this article. First, Rawls regards his two principles as established or justified not simply by the fact that they would be chosen, as he claims they would, by the parties in the original position, but also by the general harmony of these principles with ordinary "considered judgments duly pruned and adjusted."'5 The test of his theory, therefore, is in part whether the principles he identifies illuminate our ordinary judgments and help to reveal a basic structure and coherence underlying them.

Secondly, it is an important and interesting feature of Rawls's theory that once the principles of justice have been chosen we come to understand what their implementation would require by imagining a fourstage process. Thus, we are to suppose that after the first stage, when the parties in the original position have chosen the principles of justice, they move to a constitutional convention. There, in accordance with the chosen principles, they choose a constitution and establish the basic rights or liberties of citizens. The third stage is that of legislation, where the justice of laws and policies is considered; enacted statutes, if they are to be just, must satisfy both the limits laid down in the constitution and the originally chosen principles of justice. The fourth and last stage is that of the application of rules by judges and other officials to particular cases.

\section{LIBERTY AND BASIG LIBERTIES}

Throughout his book Rawls emphasises the distinction between liberty and other social goods, and his principle of greatest equal liberty is,

4 P. 302. I have here omitted the provisions for a just savings principle and for equality of opportunity, which Rawls includes in this formulation of his second principle, since they are not relevant to the present discussion.

5 P. 20. Rawls, in fact, speaks of a "reflective equilibrium" between principles and ordinary judgments, since he envisages that where there are initial discrepancies between these we have a choice of modifying the conditions of the initial position in which principles are chosen or modifying in detail the judgments. Pp. $20 \mathrm{ff}$. 
as I have said, accompanied-in his special conception of justice as distinct from his general conception-by a priority rule which assigns to liberty, or at least to certain forms of liberty institutionally defined and protected, a priority which forbids the restriction of liberty for the sake of other benefits: liberty is only to be restricted for the sake of liberty itself. In the general conception of justice there is no such priority rule and no requirement that liberty must be as extensive as possible, though it is to be equally distributed unless an unequal distribution of it is justified as being to everyone's advantage. ${ }^{6}$ The special conception is to govern societies which have developed to the point when, as Rawls says, "the basic wants of individuals can be fulfilled"7 and social conditions allow "the effective establishment of fundamental rights." If these favourable conditions do not obtain, equal liberty may be denied, if this is required to "raise the level of civilization so that in due course these freedoms can be enjoyed."

I find it no easy matter, on some quite crucial points, to interpret Rawls's complex doctrine, and there is one initial question of interpretation which I discuss here at some length. But it is perhaps worth saying that to do justice to Rawls's principle of greatest equal liberty it is necessary to take into account not only what he says when expressly formulating, expounding, and illustrating this principle, but also what he says about some other apparently separate issues-in particular, natural duties, ${ }^{10}$ obligations arising from the principle of fairness, ${ }^{11}$ permissions, ${ }^{12}$ paternalism, ${ }^{13}$ and the common good or common interest, ${ }^{14}$ for these may apparently supplement the rather exiguous provision for restrictions on liberty which are all that, at first sight, his principle of greatest equal liberty seems to allow.

The initial question of interpretation arises from the following circumstances. Rawls in his book often refers in broad terms to his first principle of justice as "the principle of greatest equal liberty,"15 and in similarly broad terms to its associated priority rule as the rule that "liberty can be restricted only for the sake of liberty." 16 These references

\footnotetext{
6 P. 62.

7 P. 543.

8 Pp. 152, 542.

9 P. 152.

10 Pp. 114 ff, 333 ff.

11 Pp. 108 ff.

12 Pp. 116 ff.

13 P. 248.

14 Pp. 97, 213, 246.

15 E.g., p. 124.

10 Pp. 250, 302.
} 
to liberty in quite general terms, and also Rawls's previous formulation in his articles of this first principle as the principle that everyone has "an equal right to the most extensive liberty compatible with a like liberty for all,"17 suggest that his doctrine is similar to that criticized by Sidgwick. ${ }^{18}$ It is probable that Sidgwick had chiefly in mind a formulation of a principle of greatest equal liberty urged by Herbert Spencer in his long forgotten Social Statics. ${ }^{19}$ This was effectively criticised by Sidgwick as failing to account for some of the most obvious restrictions on liberty required to protect individuals from harms other than constraint or deprivation of liberty, and indeed as forbidding the institution of private property, since to own anything privately is to have liberty to use it in ways denied to others. Spencer attempted to get out of this difficulty (or rather outside it) by simply swallowing it, and reached the conclusion that, at least in the case of land, only property held in common by a community would be consistent with "equal liberty" 20 and hence legitimate. Rawls in his book simply lists without argument the right to hold personal property, but not property in the means of production, as one of the basic liberties, ${ }^{21}$ though, as I shall argue later, he does this at some cost to the coherence of his theory.

Rawls's previous formulation of his general principle of greatest equal liberty- -"everyone has an equal right to the most extensive liberty compatible with a like liberty for all"-was then very similar to the doctrine criticised by Sidgwick. But Rawls's explicit formulation of it in his book is no longer in these general terms. It refers not to "liberty" but to basic or fundamental liberties, which are understood to be legally recognised and protected from interference. This, with its priority rule, as finally formulated, now runs as follows:

Each person is to have an equal right to the most extensive total system of equal basic liberties compatible with a similar system of liberty for all....

17 Rawls, Justice as Fairness, 67 Phuosophical Review 164, 165 (1958); see Rawls, The Sense of Justice, 72 Philosophical Review 283 (1963); J. Rawls, Distributive Justice, in Politics, Philosophy AND Society 61 (3d Series, Oxford 1967). This formulation in these articles should not be confused with the formulation of the "general conception" of justice in the book. See pp. 3 ff.

18 H. SibGwick, supra note I, Book IIr, Ch. V., §§ 4-5 and Ch. XI, § 5.

19 See H. Spencer, Soctal Statics (1850). Criticisms of Spencer's theory in terms very similar to Sidgwick's criticisms were made by $F$. W. Maitland in 1 Collected PAPERS 247 (H. Fisher ed. 1911). Maitland treated Spencer's doctrine of equal liberty as virtually identical with Kant's notion of mutual freedom under universal law expounded in the latter's Rechtslehre. I am grateful to Professor B.J. Diggs for pointing out to me important differences between Rawls's doctrine of liberty and Kant's conception of mutual freedom under universal law.

$20 \mathrm{H}$. SPENCER, supra note 19.

21 P. 61. 
[L]iberty can be restricted only for the sake of liberty. There are two cases: (a) a less extensive liberty must strengthen the total system of liberty shared by all; (b) a less than equal liberty must be acceptable to those with the lesser liberty. ${ }^{22}$

Even to this, however, for complete accuracy a gloss on the last sentence is needed because Rawls also insists that "acceptable to those with the lesser liberty" means not acceptable just on any grounds, but only acceptable because affording a greater protection of their other liberties. ${ }^{23}$

The basic liberties to which Rawls's principle thus refers are identified by the parties in the original position ${ }^{24}$ from behind the veil of ignorance as essential for the pursuit of their ends, whatever those ends turn out to be, and so as determining the form of their society. Not surprisingly, therefore, the basic liberties are rather few in number and Rawls gives a short list of them which he describes in the index as an "enumeration," 25 though he warns us that these are what they are only "roughly speaking." 20 They comprise political liberty, that is, the right to vote and be eligible for public office, freedom of speech and of assembly; liberty of conscience and freedom of thought; freedom of the person, along with the right to hold personal property; and freedom from arbitrary arrest and seizure.

Now the question of interpretation is whether Rawls's change of language from a principle of greatest equal liberty couched in quite general terms ("everyone has an equal right to the most extensive liberty"), to one referring only to specific basic liberties, indicates a change in his theory. Is the principle of liberty in the book still this quite general principle, so that under the priority rule now attached to it no form of liberty may be restricted except for the sake of liberty? It is difficult to be sure, but my own view on this important point is that Rawls no longer holds the quite general theory which appeared in his articles, perhaps because he had met the difficulties pointed out by Sidgwick and others. There are, I think, several indications, besides the striking change in language, that Rawls's principle is now limited to the list of basic liberties, allowing of course for his statement that the actual list he gives is only rough. The first indication is the fact that Rawls does not find it necessary to reconcile the admission of private property as a liberty with any general principle of maximum equal liberty, or of "an equal right to the most extensive liberty," and he avoids the difficulties

22 P. 302.

23 P. 233.

24 E.g., "equal liberty of conscience is the only principle that parties in the original position can acknowledge." P. 207.

25 P. 540.

26 P. 61. 
found in Herbert Spencer's doctrine by giving a new sense to the requirement that the right to hold property must be equal. This sense of equality turns on Rawls's distinction between liberty and the value or worth of liberty. ${ }^{27}$ Rawls does not require, except in the case of the political liberties (the right to participate in government and freedom of speech), that basic liberties be equal in value, or substantially equal, so he does not require, in admitting the right to property as a basic equal liberty, either that property should be held in common so that everyone can enjoy the same property or that separately owned property should be equal in amount. That would be to insist that the value of the right to property should be equal. What is required is the merely formal condition that the rules $^{28}$ governing the acquisition, disposition, and scope of property rights should be the same for all. Rawls's reply to the familiar Marxist criticism that in this case we shall have to say that the beggar and the millionaire have equal property rights would be to admit the charge, but to point out that, in his system, the unequal value of these equal property rights would be cut down to the point where inequality would be justified by the working of the difference principle, according to which economic inequalities are justified only if they are for the benefit of the least advantaged. ${ }^{29}$

The second indication that Rawls's principle of greatest equal liberty and its priority rule ("liberty can be restricted only for the sake of liberty") $)^{30}$ is now limited to the basic liberties is his careful and repeated explanation that, though the right to hold property is for him a "liberty," the choice between private capitalism and state ownership of the means of production is left quite open by the principles of justice. ${ }^{31}$ Whether or not the means of production are to be privately owned is something which a society must decide in the light of the knowledge of its actual circumstances and the demands of social and economic efficiency. But, of course, a decision to limit private ownership to consumer goods made on such grounds would result in a less extensive form of liberty than would obtain if private ownership could be exercised over all forms of property. Rawls's admission of this restriction as allowable so far as justice is concerned would be a glaring inconsistency if he was still advancing the general principle that there must be "an equal right to the most extensive liberty," for that, under the priority rule, would entail that no form of liberty may be narrowed

$27 \mathrm{Pp} .204,225 \mathrm{ff}$.

28 Pp. 63-64.

29 P. 204.

30 P. 302.

31 Pp. 66, 273-74. 
or limited for the sake of economic benefits, but only for the sake of liberty itself.

These considerations support very strongly the interpretation that Rawls's principle of greatest equal liberty, as it is developed in this book, is concerned only with the enumerated basic liberties, though of course these are specified by him only in broad terms. But I confess that there are also difficulties in this interpretation which suggest that Rawls has not eliminated altogether the earlier general doctrine of liberty, even though that earlier doctrine is not, as I have explained above, really consistent with Rawls's treatment of the admissible limitations of the right of property. For it seems obvious that there are important forms of liberty-sexual freedom and the liberty to use alcohol or drugs among them-which apparently do not fall within any of the roughly described basic liberties; ${ }^{32}$ yet it would be very surprising if principles of justice were silent about their restriction. Since John Stuart Mills's essay On Liberty, such liberties have been the storm centre of discussions of the proper scope of the criminal law and other forms of social coercion, and there is, in fact, just one passage in this book from which it is clear that Rawls thinks that his principles of justice are not silent as to the justice of restricting such liberties. ${ }^{33}$ For in arguing against the view that certain forms of sexual relationship should be prohibited simply as degrading or shameful, and so as falling short of some "perfectionist" ideal, Rawls says that we should rely not on such perfectionist criteria but on the principles of justice and that according to these no reasonable case for restriction can be made out.

There is much that I do not understand in this short passage. Rawls says here that justice requires us to show, before restricting such modes of conduct, either that they interfere with the basic liberties of others or that "they violate some natural duty or some obligation." This seems an unexplained departure from the strict line so often emphasised in the case of basic liberties, that liberty may be restricted only for the sake of liberty. Is there then a secondary set of principles for nonbasic

32 It has been suggested to me that Rawls would regard these freedoms as basic liberties falling under his broad category of liberty of conscience, which is concerned not only with religious but with moral freedom. But Rawls's discussion of this, pp. $205 \mathrm{ff}$, seems to envisage only a man's freedom to fulfill moral obligations as he interprets them, and sexual freedom would therefore only fall under this category for those to whom the promptings of passion presented themselves as calls of moral duty. Others have suggested that these freedoms would fall under Rawls's category of freedom of the person; but this seems most unlikely to me in view of his collocation of it with property ("freedom of the person along with the right to hold personal property"). It is to be noted also that sexual freedom is spoken of as a "mode of conduct," p. 331, and the possibility of its interference with "basic liberties" (not "other" basic liberties) is mentioned.

33 P. 331. 
liberties? This solution would have its own difficulties. The natural duties to which Rawls refers here, and the principle from which obligations, such as the obligation to keep a promise, derive, are, according to Rawls, standards of conduct for individuals which the parties in the original position have gone on to choose after they have chosen the principles of justice as standards for institutions, which I take it include the law. If liberty may be restricted to prevent violation of any such natural duties or obligations, this may rather severly narrow the area of liberty, for the natural duties include the duty to assist others when this can be done at small cost and the duty to show respect and courtesy, as well as duties to support just institutions, not to harm the innocent, and not to cause unnecessary suffering. Further, since the parties in the original position are said to choose the principles of justice as standards for institutions before they choose the natural duties for individuals, it is not clear how the former can incorporate the latter, as Rawls suggests they do when he says that principles of justice require us to show, before we restrict conduct, that it violates either basic liberties or natural duties or obligations.

I hope that I have not made too much of what is a mere passing reference by Rawls to liberties which do not appear to fall within his categories of basic liberties, but have been at the centre of some famous discussions of freedom. I cannot, however, from this book see quite how Rawls would resolve the difficulties I have mentioned, and I raise below the related question whether liberties which are plainly "basic" may also be restricted if their exercise involves violation of natural duties or obligations.

\section{Limiting LIBERTY FOR THE SAKE OF LIBERTY}

I turn now to consider the principle that basic liberties may be limited only for the sake of liberty. Rawls expresses this principle in several different ways. He says that basic liberties may be restricted or unequally distributed only for the sake of a greater "system of liberty as a whole"; 34 that the restriction must yield "a greater equal liberty,"35 or "the best total system of equal liberty" 30 or "strengthen" that system, ${ }^{37}$ or be "a gain for ... freedom on balance." 38

What, then, is it to limit liberty for the sake of liberty? Rawls gives a number of examples which his principle would permit. The simplest 
case is the introduction of rules of order in debate, ${ }^{39}$ which restrict the liberty to speak when we please. Without this restriction the liberty to say and advocate what we please would be grossly hampered and made less valuable to us. As Rawls says, such rules are necessary for "profitable" 40 discussion, and plainly when such rules are introduced a balance is struck and the liberty judged less important or less valuable is subordinated to the other. In this very simple case there seems to be a quite obvious answer to the question as to which of the two liberties here conflicting is more valuable since, whatever ends we are pursuing in debate, the liberty to communicate our thought in speech must contribute more to their advancement than the liberty to interrupt communication. It seems to me, however, misleading to describe even the resolution of the conflicting liberties in this very simple case as yielding a "greater" or "stronger" total system of liberty, for these phrases suggest that no values other than liberty and dimensions of it, like extent, size, or strength, are involved. Plainly what such rules of debate help to secure is not a greater or more extensive liberty, but a liberty to do something which is more valuable for any rational person than the activities forbidden by the rules, or, as Rawls himself says, something more "profitable." So some criterion of the value of different liberties must be involved in the resolution of conflicts between them; yet Rawls speaks as if the system "of basic liberties" were self-contained, and conflicts within it were adjusted without appeal to any other value besides liberty and its extent.

In some cases, it is true, Rawls's conception of a greater or more extensive liberty resulting from a more satisfactory resolution of conflicts between liberties may have application. One fairly clear example is provided by Rawls when he says that the principle of limiting liberty only for the sake of liberty would allow conscription for military service in a war genuinely undertaken to defend free institutions either at home or abroad. ${ }^{41}$ In that case it might plausibly be said that only the quantum or extent of liberty was at stake; the temporary restriction of liberty involved in military conscription might be allowed to prevent or remove much greater inroads on liberty. Similarly, the restriction imposed in the name of public order and security, to which Rawls often refers, ${ }^{42}$ may be justified simply as hindering greater or more extensive hindrances to liberty of action. But there certainly are important cases of conflict between basic liberties where, as in the simple rules of

39 P. 203.

$40 I d$.

41 P. 380.

42 Pp. 97, 212-13. 
debate case, the resolution of conflict must involve consideration of the relative value of different modes of conduct, and not merely the extent or amount of freedom. One such conflict, which, according to Rawls's four-stage sequence, will have to be settled at a stage analogous to a constitutional convention, is the conflict between freedom of speech and of the person, and freedom to participate in government through a democratically elected legislature. ${ }^{43}$ Rawls discusses this conflict on the footing that the freedom to participate in government is to be considered as restricted if there is a Bill of Rights protecting the individual's freedom of speech or of the person from regulation by an ordinary majority vote of the legislature. He says that the kind of argument to support such a restriction, which his principles of justice require, is "a justification which appeals only to a greater equal liberty." 44 He admits that different opinions about the value of the conflicting liberties will affect the way in which different persons view this conflict. Nonetheless, he insists that to arrive at a just resolution of the conflict we must try to find the point at which "the danger to liberty from the marginal loss in control over those holding political power just balances the security of liberty gained by the greater use of constitutional devices." 45 I cannot myself understand, however, how such weighing or striking of a balance is conceivable if the only appeal is, as Rawls says, to "a greater liberty."

These difficulties in the notion of a greater total liberty, or system of liberty, resulting from the just resolution of conflict between liberties, are made more acute for me by Rawls's description of the point of view from which he says all such conflicts between liberties are to be settled -whether they occur at the constitution making stage of the four-stage sequence, as in the case last considered, or at the stage of legislation in relation to other matters.

Rawls says that when liberties conflict the adjustment which is to secure "the best total system" is to be settled from the standpoint of "the representative equal citizen," and we are to ask which adjustment "it would be rational for him to prefer."46 This, he says, involves the application of the principle of the common interest or common good which selects those conditions which are necessary for "all to equally further their aims" or which will "advance shared ends." ${ }^{47}$ It is, of course, easy to see that very simple conflicts between liberties, such as the de-

43 Pp. 228-30.

44 P. 229.

45 P. 230.

46 P. 204.

47 P. 97. 
bating rules case, may intelligibly be said to be settled by reference to this point of view. For in such simple cases it is certainly arguable that, whatever ends a man may have, he will see as a rational being that the restrictions are required if he is to pursue his ends successfully, and this can be expressed in terms of "the common good" on the footing that such restrictions are necessary for all alike. But it would be quite wrong to generalize from this simple case; other conflicts between basic liberties will be such that different resolutions of the conflict will correspond to the interests of different people who will diverge over the relative value they set on the conflicting liberties. In such cases, there will be no resolution which will be uniquely selected by reference to the common good. So, in the constitutional case discussed above, it seems difficult to understand how the conflict can be resolved by reference to the representative equal citizen, and without appeal to utilitarian considerations or to some conception of what all individuals are morally entitled to have as a matter of human dignity or moral right. In particular, the general strategy which Rawls ascribes to the parties in the original position of choosing the alternative that yields the best worst position is no help except in obvious cases like the debating rules case. There, of course, it can be argued that it is better to be restricted by reasonable rules than to be exposed to unregulated interruption, so that it is rational to trade off the liberty to speak when you please for the more valuable benefit of being able to communicate more or less effectively what you please. Or, to put the same exceedingly simple point in the "maximin" terms which Rawls often illuminatingly uses, the worst position under the rule (being restrained from interruption but given time to speak free from interruption) is better than the worst position without the rule (being constantly exposed to interruption though free to interrupt).

Such simple cases, indeed, exist where it can be said that all "equal citizens," however divergent their individual tastes or desires, would, if rational, prefer one alternative where liberties conflict. But I do not understand how the notion of the rational preference of the representative equal citizen can assist in the resolution of conflicts where reasonable men may differ as to the value of conflicting liberties, and there is no obviously best worst position which a rational man would prefer. It is true that at the stages in the four-stage sequence where such conflicts have to be resolved there is no veil of ignorance to prevent those who have to take decisions knowing what proportions of the population favour which alternatives. But I do not think Rawls would regard such knowledge as relevant in arguments about what it would be rational for the representative equal citizen to prefer; for it would only be rele- 
vant if we conceive that this representative figure in some way reflects (perhaps in the relative strength or intensity of his conflicting desires) the distribution of different preferences in the population. This, however, would be virtually equivalent to a utilitarian criterion and one that I am sure is far from Rawls's thoughts. I would stress here that I am not complaining that Rawls's invocation of "the rational preference of the representative equal citizen" fails to provide a decision procedure yielding a determinate answer in all cases. Rather, I do not understand, except in the very simple cases, what sort of argument is to be used to show what the representative's rational preference would be and in what sense it results in "a greater liberty."

Of course, it is open to Rawls to say, as he does, that arguments concerning the representative's rational preference will often be equally balanced, and in such cases justice will be indeterminate. But I do not think that he can mean that justice is to be indeterminate whenever different people value alternatives differently. Indeed, he is quite clear that, in spite of such difference in valuation, justice does require that there be some constitutional protections for individual freedom, though these will limit the freedom to participate in government; ; $^{48}$ the only indeterminacy he contemplates here is as to the particular form of constitutional protection to be selected from a range of alternatives all of which may be permitted by principles of justice. Yet, if opinion is divided on the main issue (that is, whether there should be any or no restrictions on legislative power to protect individual freedom), I do not understand what sort of argument it is that is supposed to show that the representative equal citizen would prefer an affirmative answer on this main issue as securing "the greater liberty."

This difficulty still plagues me even in relatively minor cases where one might well accept a conclusion that principles of justice are indeterminate. Thus, suppose the legislator has to determine the scope of the rights of exclusion comprised in the private ownership of land, which is for Rawls a basic liberty, ${ }^{49}$ when this basic liberty conflicts with others. Some people may prefer freedom of movement not to be limited

48 "The liberties of equal citizenship must be incorporated into and protected by the constitution." P. 197. "If a bill of rights guaranteeing liberty of conscience and freedom of thought and assembly would be effective then it should be adopted." P. 231.

49 It has been suggested to me by Mr. Michael Lesnoff that Rawls might not consider the private ownership of land to be a basic liberty since, as noted above, justice according to Rawls leaves open the question whether there is to be private ownership of the means of production. I am not, however, clear what is included in the scope of the basic liberty which Rawls described as "the right to hold [personal] property." P. 61. Would it comprise ownership or (in a socialized economy) a tenancy from the state in land to be used as a garden? If not, the example in the text might be changed to that of a conflict between pedestrians' freedom of movement and the rights of automobiles. 
by the rights of landowners supported by laws about trespass; others, whether they are landowners or not, may prefer that there be some limitations. If justice is indeterminate in this minor case of conflicting liberties, then no doubt we would fall back on what Rawls terms procedural justice, and accept the majority vote of a legislature operating under a just constitution and a fair procedure, even if we cannot say of the outcome that it is in itself a just one. But, presumably, in considering what measures to promote and how to vote, the legislators must, since this is a case, though a minor one, of conflicting basic liberties, begin by asking which of the alternatives a representative equal citizen would, if rational, prefer, even if they are doomed to discover that this question has no determinate answer. But indeterminacy and unintelligibility are different things, and it is the intelligibility of the question with which I am concerned. What do the legislators mean in such cases when they ask which alternative it would be rational for the representative equal citizen to prefer as securing the greater liberty, when they know that some men may value privacy of property more than freedom of movement, and others not? If the question is rephrased, as Rawls says it can be, as a question involving the principle of the common good, then it will presumably appear as the question which alternative will in the long run most advance the good of all, or ends that all share. This might be an answerable question in principle if it could be taken simply as the question which alternative is likely most to advance everyone's general welfare, where this is taken to include economic and other advantages besides liberty. If, for example, it could be shown that unrestricted freedom of movement over land would tend to reduce everyone's food supply, whereas no bad consequences likely to affect everyone would result from the other alternative, then the conflict should be resolved in favour of restriction of movement. But this interpretation of the question in terms of welfare seems ruled out by the principle that liberty may only be limited for the sake of liberty, and not for social or economic advantages. So, I think, that the conception of the rational choice of the representative equal citizen needs further clarification.

\section{Limiting Liberty to Prevent Harm or Suffering}

I now turn to the question whether the principle of limiting liberty only for the sake of liberty provides adequately for restrictions on conduct which causes pain or unhappiness to others otherwise than by constraining liberty of action. Such harmful conduct in some cases would be an exercise of the basic liberties, such as freedom of speech, for example, or the use of property, though in other cases it may be the exercise of a liberty not classed by Rawls as basic. It would be extraordinary 
if principles of justice which Rawls claims are in general in harmony with ordinary considered judgments were actually to exclude (because they limited liberty otherwise than for the sake of liberty) laws restraining libel or slander, or publications grossly infringing privacy, or restrictions on the use of private property (e.g., automobiles) designed to protect the environment and general social amenities. These restrictions on the basic liberties of speech and private property are commonly accepted as trade-offs not of liberty for liberty, but of liberty for protection from harm or loss of amenities or other elements of real utility.

There are two ways in which perhaps Rawls's principles can at least partly fill this gap. ${ }^{50}$ In some cases more plausibly than others, he might argue that an unrestricted liberty to inflict what we call harm or suffering on others would in fact restrict the victim's liberty of action in either or both of two ways. The physical injury inflicted might actually impair the capacity for action, or the knowledge that such harmful actions were not prohibited might create conditions of apprehension and uncertainty among potential victims which would grossly inhibit their actions. But such arguments seem quite unplausible except in cases of conduct inflicting serious physical harm on individuals, and even there, when such restrictions are accepted as a reasonable sacrifice of liberty, it seems clear that if pain and suffering and distress were not given a weight independent of the tendency of harmful conduct to inhibit the victim's actions or incapacitate him from action, the balance would often, in fact, not be struck as it is.

It is, however, necessary at this point again to take into account those natural duties which are standards of individual conduct, as distinct from principles of justice, which are standards for institutions. These duties include the duty not to harm others or cause "unnecessary suffering" and also the duty to come to the assistance of others. In discussing the acceptance of such duties by the parties in the original position, Rawls represents them as calculating that the burdens of such duties will be outweighed by the benefits; ${ }^{51}$ so natural duties represent cases

50 Professor Dworkin and Mr. Michael Lesnoff have suggested to me that what I describe here as a "gap" may not in fact exist, since Rawls's basic liberties may be conceived by him as limited $a b$ initio so that they do not include the liberty to act in a way damaging to the interests or liberties of others. But though it is certainly consistent with much of Rawls's discussion of basic liberties to treat his admittedly rough description of them as simply indicating areas of conduct within which the parties in the original position identify specific rights after resolving conflicts between the several liberties and the interests or liberties of others, this does not fit with Rawls's account of the basic liberties as liable to conflict, nor with his account of the conflicts as resolved not by the parties in the original position but by constitutional convention or body of legislators adopting the point of view of the representative equal citizen.

61 P. 338. 
where, like the simple rules of debate case, the best worst position for all rational men can be identified, and in these cases even from behind the veil of ignorance. Even there it will appear to the parties as rational self-interested persons that it is, for example, better to be restrained from practising cruelty to others while protected from them than to be exposed to others' cruelty while free to practise it, and better to have to provide modest assistance to others in need than never to be able to rely on such assistance being forthcoming. So it is plain that these natural duties might fill part of the gap left open by the principle that liberty may only be limited for the sake of liberty, if Rawls means (though he does not explicitly say it) that even the basic liberties may be restricted if their exercise would infringe any natural duty. But again, these natural duties chosen from behind the veil of ignorance would only account for very obvious cases where the benefits of the restrictions would, for all rational men, plainly outweigh the burdens. This will not help where divergent choices could reasonably be made by different individuals in the light of their different interests, and it seems to me that this will very often be the case. Some persons, given their general temperament, might reasonably prefer to be free to libel others or to invade their privacy, or to make use of their own property in whatever style they like, and might gladly take the risk of being exposed to these practices on the part of others and to the consequences of such practices for themselves and the general social and physical environment. Other persons would not pay this price for unrestricted liberty in these matters, since, given their temperament, they would value the protections afforded by the restrictions higher than the unrestricted liberty. In such cases restrictions on the basic liberties of speech or private property cannot be represented as a matter of natural duty on the footing that rational men, whatever their particular temperament, would opt for the restrictions just as they might opt for general restrictions on killing or the use of violence.

Of course, it is certainly to be remembered that justice for Rawls does not exhaust morality; there are, as he tells us, requirements, indeed duties, in relation to animals and even in relation to the rest of nature which are outside the scope of a theory of justice as a theory of what is owed to rational individuals. ${ }^{62}$ But even if there are such moral duties, regarding even rational beings, I do not think that Rawls would consider them as supplementing principles of justice which apply to institutions. I take it, therefore, that restrictions on the basic liberties excluded by the principles of justice because they are not restrictions of liberty for the sake of liberty could not be independently supported

62 P. 512. 
as just by appeal to other principles of morality. The point here is not that Rawlsian justice will be shown to be indeterminate at certain points as to the propriety of certain restrictions on liberty; it is, on the contrary, all too determinate since they seem to exclude such restrictions as actually unjust because they do not limit liberty only for the sake of liberty. I take it Rawls would not wish to meet this point by simply adding to his principles of justice a further supplement permitting liberty to be restricted if its exercise violated not only the natural duties but any requirements of morality, for this would, it seems to me, run counter to the general liberal tenor of his theory.

\section{The Ghoice of Basic Liberties}

I think the most important general point which emerges from these separate criticisms is as follows. Any scheme providing for the general distribution in society of liberty of action necessarily does two things: first, it confers on individuals the advantage of that liberty, but secondly, it exposes them to whatever disadvantages the practices of that liberty by others may entail for them. These disadvantages include not only the case on which Rawls concentrates, namely interference with another individual's basic liberties, but also the various forms of harm, pain, and suffering against which legal systems usually provide by restrictive rules. Such harm may also include the destruction of forms of social life or amenities which otherwise would have been available to the individual. So whether or not it is in any man's interest to choose that any specific liberty should be generally distributed depends on whether the advantages for him of the exercise of that liberty outweigh the various disadvantages for him of its general practice by others. I do not think Rawls recognises this adequately in his discussion of conflicting liberties and his theory of natural duties. His recognition is inadequate, I think, because his doctrine insists that liberty can only be limited for the sake of liberty, and that when we resolve conflicts we must be concerned only with the extent or amount of liberty. This conceals the character of the advantages and disadvantages of different sorts which must be involved in the resolution of such conflicts; and his doctrine also leads him to misrepresent the character of all except those most simple conflicts between liberty and other benefits which are resolved by the parties in the original position when they choose the natural duties. Throughout, I think, Rawls fails to recognise suffciently that a weighing of advantage and disadvantage must always be required to determine whether the general distribution of any specific liberty is in a man's interest, since the exercise of that liberty by others 
may outweigh the advantages to him of his own exercise of it. A rather startling sign that this is ignored appears in Rawls's remark that "from the standpoint of the original position, it is rational" for men to want as large a share as possible of liberty, since "they are not compelled to accept more if they do not wish to, nor does a person suffer from a greater liberty." 53 This I find misleading because it seems to miss the vital point that, whatever advantage for any individual there may be in the exercise of some liberty taken in itself, this may be outweighed by the disadvantages for him involved in the general distribution of that liberty in the society of which he is a member.

The detailed criticisms which I have made so far concern the application of Rawls's principle of greatest equal liberty. But the general point made in the last paragraph, if it is valid, affects not merely the application of the principles of justice once they have been chosen but also the argument which is designed to show that the parties would in the conditions of the original position, as rational self-interested persons, choose the basic liberties which Rawls enumerates. Even if we assume with Rawls that every rational person would prefer as much liberty as he can get if no price is to be paid for it, so that in that sense it is true that no one "suffers from a greater liberty," it does not follow that a liberty which can only be obtained by an individual at the price of its general distribution through society is one that a rational person would still want. Of course, Rawls's natural duties represent some obvious cases where it can fairly be said that any rational person would prefer certain restrictions to a generalised liberty. In other, less simple cases, whether it would be rational to prefer liberty at the cost of others having it too must depend on one's temperament and desires. But these are hidden from the parties in the original position and, this being so, I do not understand how they can make a rational decision, in terms of self-interest, to have the various liberties at the cost of their general distribution. Opting for the most extensive liberty for all cannot, I think, be presented as always being the best insurance against the worst in conditions of uncertainty about one's own temperament and desires.

\section{The Argument for the Priority of Liberty}

I will end by explaining a difficulty which I find in the main argument which Rawls uses to show that the priority of liberty prohibiting exchanges of liberty for economic or other social advantages must be included among the requirements of justice. According to Rawls's theory, the rational, self-interested parties in the original position choose

53 P. 143. 
this priority rule from behind the veil of ignorance as part of the special conception of justice, but they choose it on the footing that the rule is not to come into play unless or until certain favourable social and economic conditions have actually been reached in the society of which they will be members. These favourable conditions are identified as those which allow the effective establishment and exercise of the basic liberties, ${ }^{54}$ and when basic wants can be fulfilled. ${ }^{55}$ Until this point is reached the general conception of justice is to govern the society, and men may give up liberties for social and economic gains if they wish.

I do not think that Rawls conceives of the conditions which bring the priority rule into play as a stage of great prosperity.$^{56}$ At any rate, it is quite clear that when this stage is reached there may still be in any society people who want more material goods and would be willing to surrender some of their basic liberties to get them. If material prosperity at this stage were so great that there could then be no such people, the priority rule then brought into operation could not function as a prohibitory rule, for there would be nothing for it to rule out. As Rawls says, we need not think of the surrender of liberties which men might still be willing to make for greater economic welfare in very extreme terms, such as the adoption of slavery. ${ }^{57}$ It might be merely that some men, perhaps a majority, perhaps even all, in a society might wish to surrender certain political rights the exercise of which does not appear to them to bring great benefits, and would be willing to let government be carried on in some authoritarian form if there were good reasons for believing that this would bring a great advance in material prosperity. It is this kind of exchange which men might wish to make that the priority rule forbids once a society has reached the quite modest stage where the basic liberties can be effectively established and the basic wants satisfied.

\footnotetext{
54 P. 152.

55 Pp. 542-43.

156 It is plain that under this identification the conditions for the application of the special conception of justice may be reached at very different levels of material prosperity in different societies. Thus, in a small agrarian society or in a society long used to hard conditions, men might be capable of establishing and exercising political liberties at a much lower standard of living than would be possible for inhabitants of a large, modern industrial society. But in view of the fact that Rawls describes the relevant stage as one where conditions merely "allow" or "admit" the effective establishment and realisation of basic liberties, it is not clear to me whether he would consider the special conception of justice applicable to a very wealthy society where, owing to the unequal distribution of wealth, poverty prevented considerable numbers from actually exercising the basic liberties. Would it be unjust for the poor in such a society to support an authoritarian form of government to advance their material conditions?
}

57 P. 61. 
Why then should this restrictive priority rule be accepted as among the requirements of justice? Rawls's main answer seems to be that, as the conditions of civilisation improve, a point will be reached when from the standpoint of the original position, "it becomes and then remains . . . irrational to acknowledge a lesser liberty for the sake of greater material means . . . ." because, "as the general level of well-being rises, only the less urgent material wants remain" 58 to be satisfied and men come increasingly to prize liberty. "The fundamental interest in determining our plan of life eventually assumes a prior place" and "the desire for liberty is the chief regulative interest that the parties [in the original position] must suppose they all will have in common in due course." 59 These considerations are taken to show the rationality, from the standpoint of the parties in the original position, of ranking liberty over material goods, represented by the priority rule.

The core of this argument seems to be that it is rational for the parties in the original position, ignorant as they are of their own temperaments and desires and the conditions of the society of which they are to be members, to impose this restriction on themselves prohibiting exchanges of liberty for other goods because "eventually" or "in due course" in the development of that society the desire for liberty will actually come to have a greater attraction for them. But it is not obvious to me why it is rational for men to impose on themselves a restriction against doing something they may want to do at some stage in the development of their society because at a later stage ("eventually" or "in due course") they would not want to do it. There seems no reason why a surrender of political liberties which men might want to make purely for a large increase in material welfare, which would be forbidden by the priority rule, should be permanent so as to prevent men, when great affluence is reached, restoring the liberties if they wished to do so; it is not as if men would run the risk, if there were no priority rule, of permanently losing liberties which later they might wish to have. I think, however, that probably Rawls's argument is really of the following form, which makes use again of the idea that under certain conditions of uncertainty rational beings would opt for the alternative whose worst consequences would be least damaging to one's interests than the worst consequences of other alternatives. Since the parties in the original position do not know the stage of development of their society, they must, in considering whether to institute a priority rule prohibiting exchanges of liberty for economic goods, ask themselves which of the following alternatives, A or B is least bad:

68 P. 542.

59 P. 543 (emphasis added). 
A. If there is no priority rule and political liberties have been surrendered in order to gain an increase in wealth, the worst position is that of a man anxious to exercise the lost liberties and who cares nothing for the extra wealth brought him by surrender.

$\mathrm{B}$. If there is a priority rule, the worst position will be that of a person living at the bottom economic level of society, just prosperous enough to bring the priority rule into operation, and who would gladly surrender the political liberties for a greater advance in material prosperity.

It must, I think, be part of Rawls's argument that for any rational selfinterested person $B$ is the best worse position and for that reason the parties in the original position would choose it. I am not sure that this is Rawls's argument, but if it is, I do not find it convincing. For it seems to me that here again the parties in the original position, ignorant as they are of the character and strength of their desires, just cannot give any determinate answer if they ask which of the positions, $\mathrm{A}$ or $\mathrm{B}$, it is then, in their condition of ignorance, most in their interests to choose. When the veil of ignorance is lifted some will prefer $A$ to $B$ and others B to $\mathrm{A}$.

It may be that a better case along the line of argument just considered could be made out for some of the basic liberties, for example, religious freedom, than for others. It might be said that any rational person who understood what it is to have a religious faith and to wish to practise it would agree that for any such person to be prevented by law from practising his religion must be worse than for a relatively poor man to be prevented from gaining a great advance in material goods through the surrender of a religious liberty which meant little or nothing to him. But even if this is so, it seems to me that no general priority rule forbidding the exchange, even for a limited period, of any basic liberty which men might wish to make in order to gain an advance in material prosperity, can be supported by this argument which I have ascribed, possibly mistakenly, to Rawls.

I think the apparently dogmatic course of Rawls's argument for the priority of liberty may be explained by the fact that, though he is not offering it merely as an ideal, he does harbour a latent ideal of his own, on which he tacitly draws when he represents the priority of liberty as a choice which the parties in the original position must, in their own interest, make as rational agents choosing from behind the veil of ignorance. The ideal is that of a public-spirited citizen who prizes political activity and service to others as among the chief goods of life and could not contemplate as tolerable an exchange of the opportunities for such activity for mere material goods or contentment. This ideal 
powerfully impregnates Rawls's book at many points which I have been unable to discuss here. It is, of course, among the chief ideals of Liberalism, but Rawls's argument for the priority of liberty purports to rest on interests, not on ideals, and to demonstrate that the general priority of liberty reflects a preference for liberty over other goods which every self-interested person who is rational would have. Though his argument throws much incidental light on the relationship between liberty and other values, I do not think that it succeeds in demonstrating its priority. 